\title{
REPRESENTAÇÕES DA BELLE-ÉPOQUE. A ILUSÃO E AS MARCAS DE UMA SOCIEDADE EM TRANSFORMAÇÃO
}

Maria de Fátima da Silva Costa Garcia Mattos ${ }^{1}$

É na segunda metade do século XIX, que a influência francesa atinge o seu auge no Brasil, determinando os modelos da vida social e cultural, através das suas referências intelectuais e filosóficas, como as da pintura, da decoração, da culinária e da moda.

$\mathrm{Na}$ maioria dos textos da extensa lista de cronistas que caracterizaram a vida na cidade no final dos oitocentos, é freqüente a referência ao "novo", mesmo que, por vezes, não aparecesse associado ao urbano, pois, aparentemente, o "novo" não poderia vencer a resistência do passado.

Muitos cronistas saudavam esse tempo de progresso convictos de que tudo nele inspirava a mudança da fisionomia urbana exigida por uma metrópole.

No Rio de Janeiro, um cronista da revista Fon-fon resumiu todo esse espírito num rápido comentário sobre o nome dos estabelecimentos recém inaugurados na Avenida Central:

Café Chic é genial! Junto ao Chic temos o Rose - Maison Rose. Rose é otimismo, é a satisfação de viver... Chic e Rose - é a expressão do anseio da nova modernidade carioca... ( SEVCENKO 1983: 3)

Contudo, esse sentido nos remete às raízes desse processo, especialmente à Europa do século XVIII. O luxo da Corte de Luís XIV e o prestígio da literatura e da filosofia permitiram que esse ideário se espalhasse por boa parte do ocidente. Passa a fazer parte da boa formação, por exemplo, que um rapaz de boa família fosse enviado a Paris para completar a sua educação. Os bons modos, tanto na cultura como na educação e na vida mundana, eram regulados pela maneira parisiense de ver e de ser. Assim, o idioma francês era falado nas cortes européias, dominando o gosto e a elegância da fala e da expressão.

No imaginário do Rio de Janeiro, cidade que ainda possuía características coloniais e predominância das raízes portuguesas, envolver-se ou se dar conta desse novo momento mundial de euforia, otimismo e progresso, significava "europeizar-se"; portanto, para nós, civilizar-se. Era, pois, deixar para trás as marcas da antiga metrópole e com ela o conceito de "atraso" que carregava impregnado.

Dessa forma, não foi difícil, para a França, semear na cultura brasileira os seus hábitos e costumes, visto que já conviviam, no Brasil, exilados políticos e artistas, dentre outros vários profissionais da Corte, desde o início do século XIX com a chegada Missão Artística Francesa, em 1816, modificando o gosto brasileiro, como queria D.João VI, introduzindo um novo partido na arquitetura, o Neoclássico, resgatando-nos, assim, do Barroco colonial.

A pintura, a música e a literatura seguiram, nessa esteira, o mesmo caminho, definindo muitos dos parâmetros da nossa leitura artística, após o Romantismo nas artes brasileiras.

O período entre 1870 e 1920 foi representado como tempos de transformação, para o Rio de Janeiro. A cidade tornou-se documento de uma época, como foram a moda, a riqueza, a etiqueta ( manuais de conduta) envolvida com os novos hábitos, os negócios e a rápida circulação de dinheiro.

\footnotetext{
${ }^{1}$ Doutora em Artes pela ECA/USP. Docente de Estética e História da Arte nos cursos de Arquitetura e Urbanismo, Moda e Educação Artística do Centro Universitário Moura Lacerda. Ribeirão Preto (SP).
} 
Porém, nem tudo é cosmopolitismo. Enquanto o símbolo da modernidade eram as lojas caras de influência francesa, como a Casa Clarck ou a Notre Dame, na Rua Ouvidor; as casas de chá, as confeitarias e cafés, como a Colombo, o Paris ou o Provence; os clubs e cassinos que incentivavam o poker; os teatros e temporadas líricas que testemunhavam mulheres elegantemente vestidas em tafetás e chamalotes, conduzidas pelo braço de seus pares de cartola, polainas e bengala, contracenavam na cidade os analfabetos e os trabalhadores descalços, as feiras livres, as casas de cômodo e os mafuás, as favelas e cortiços, o samba e o jogo do bicho.

Machado de Assis, dentre as suas crônicas editadas como "Balas de Estalo", refere-se às novas regras para os usuários dos bondes, uma sátira aos hábitos cariocas. Muito embora cético e pessimista, ele pressentiu o ingresso da vida urbana na nova era como uma refundação dos velhos padrões de normalidade.

Com a República dos Conselheiros, a idéia de modernização alimentou o compromisso com a tradição negociando com ela o ingresso nessa tão sonhada modernidade. Essa idéia de modernização não redefiniu a feição da cidade, porém ela se reformulava constantemente, por meio dos seus intelectuais, engenheiros e bacharéis em Direito, os quais o mercado tinha marcado o seu lugar social. Comenta Sevcenko (1983:46), que Lima Barreto a denominava República Aristocrática, costumando também evocá-la por República Camaleônica.

Lima Barreto já denunciava em sua obra o que considerava a decadência moral e intelectual dos falsos modernos, visto que, para ele, o passado celebrado não passava de uma fachada mal concebida, encobrindo a dissolução dos laços de solidariedade social e a própria desumanização da cidade, continua Sevcenko (1983:162). Positivista, foi um crítico da Belle Époque, que tanto repudiava quanto o seduzia, numa avalanche de sentimentos ambíguos que o faziam investir contra o Rio - a metrópole e a sua elite.

"O Rio que emerge do seu texto é o grande centro que se metropoliza e que busca se parecer com Paris. Suprema ironia, a rachadura do espelho insistia em devolver imagens rejeitadas...", comenta Sandra Pesavento (1999:225). Na alegoria de suas leituras sobre o urbano, utilizando uma visão diferente sobre a cidade, as metáforas que emprega deixam a vida às avessas, o Brasil-Bruqundanga, onde os indivíduos não são aquilo que parecem ser, marcados pelos heróis-mártires da tragédia urbana, Policarpo da Quaresma e Clara dos Anjos, símbolos da perversa existência, num Rio que insiste em alcançar o passo da modernidade.

\footnotetext{
Na percepção do grande poeta, Olavo Bilac, a vida moderna chegara, acelerando o tempo e impondo um novo ritmo à capital do País. Segundo Bilac, "os homens de hoje são forçados a pensar e executar, em um minuto, o que seus avós executavam em uma hora. A vida moderna é feita de relâmpagos no cérebro e rufos de febre no sangue (PECHMAN e LIMA JUNIOR, 2005:36).
}

João do Rio, tomado por um outro sentimento, manifesta-se de forma diversa quanto à dissolução de algumas das melhores tradições do Império. Dizia ele que retratar o universo desagregado era uma arte e uma moda, cujas possibilidades estéticas se nutriam do popular. Personagem diagnóstico da civilização urbana (BRESCIANI, 1990), fala-nos da descrença de uma "verdadeira sociedade", um Rio de Janeiro fragmentado, na década de 1920, apoiado numa política que promovia o enriquecimento de poucos e a proliferação de famintos.

Repórter dos "espectros de rua", absorvia tudo o que sugerisse a decadência desenhada pela modernidade e valorizava aquilo que definiu como popular, presente na 
cena urbana e de seus atores: o mendigo, a prostituta, o pivete e o vagabundo, apresentados sob a regra do Art Nouveau e do espírito da Belle Époque.

Revela-se, assim, o valor da literatura para a época, a exemplo de cronistas, romancistas e memorialistas, como principal veículo de comunicação que atravessava os salões, confeitarias, livrarias, cafés e redações de jornais, onde confluíam a apologia do progresso e a crítica da decadência moral e social da nova cidade.

Os salões literários, fortemente ligados à influência francesa no Brasil, foram um importante instrumento para a socialização das mulheres, que logo passaram de meras consumidoras para produtoras de cultura. Inicialmente, os salões constituíam-se num espaço no qual as jovens de famílias abastadas podiam demonstrar seus dotes artísticos (essenciais para um bom casamento), porém, durante o Império, conforme Ângela Castro Reis, teve um papel mediador entre a burguesia e a aristocracia, num espaço onde a alegria e a informalidade quebravam barreiras de classe e de poder.

No início do período Republicano, esse sentimento de progresso já era realmente visível, por meio do crescimento econômico, da urbanização, da industrialização e do grande fluxo de imigrantes estrangeiros, através dos quais já ouvíamos os primeiros acordes da Belle Époque, cujo período configurou-se no da grande guerra européia, aproximadamente nas duas primeiras décadas do século $\mathrm{XX}$ e a partir dos últimos acontecimentos da década de 1890, no Rio de Janeiro.

A introdução dos novos hábitos e práticas de consumo foi impulsionada por um revigorado dinamismo cultural por meio das revistas ilustradas, principalmente a partir de 1900, quando a Revista da Semana passou a introduzir a publicação de fotos na sua edição. As publicações ofereciam um modelo e, de certa forma, criavam um parâmetro de comportamento social, através das referências estrangeiras, normalmente citadas, como normas de conduta. A criação do fonógrafo, das salas de cinema e dos salões de dança, bem como a difusão das práticas desportivas eram divulgadas como importantes inovações.

No que se refere à difusão das práticas desportivas, o caráter saudável da prática é também um acesso social permitido pelo conceito da renovação urbana da cidade. $O$ sanitarismo e as questões mais presentes de higiene na capital da República, também se tornaram balizadores para o conceito de familiar e individual. Agora, as casas já possuíam salas de banho mais valorizadas, desde os apetrechos rudimentares até a decoração mais requintada. A questão da higiene valorizava, por extensão, a saúde do corpo, que nesse sentido redundava em auto-estima; afinal, um corpo moderno requeria saúde, proporções e formas esbeltas, coloração da pele, elementos e procedimentos que vieram a ser objeto de destaque para os passeios ao ar livre, banhos de mar, piqueniques e freqüentes estadias em “estações de águas" ( leia-se: estâncias hidrominerais).

Com isso, homens e mulheres, que até o final século XIX se cobriam da cabeça aos pés e evitavam determinados horários de sol (as mulheres utilizavam sombrinhas, chapéus e luvas, bem como a indispensável composição das anquinhas, ombreiras e estofos para os seios e nádegas, além do espartilho para a cintura), começam a desnudar o corpo, gradativamente, como podemos observar nos retratos de época, através da diminuição dos trajes de banho. Por volta de 1915, os maiôs masculinos já se apresentavam como um conjunto de bermudas com camiseta sem mangas e os maiôs femininos sem manga e levemente decotados, cobrindo a coxa até a metade pela sobreposição de um saiote.

Por outro lado, algumas outras novidades também se instalaram, como conseqüência da nova ordem política e social na capital da República. O próprio processo de modernização, com a abertura da Avenida Central (1904-1911), atual Rio Branco, a 
reestruturação, através de um verdadeiro “ bota-abaixo” de cortiços, estalagens, sobrados e casas térreas classificadas como insalubres e indignas, sob a aparência das melhores intenções sociais "(MARINS. 2002:145), que também atingiu o Centro, desarticulou a vida boêmia desalojando os intelectuais que se reuniam nos cafés instalados no coração da cidade, circunscritos às ruas do Ouvidor e Gonçalves Dias, convidando-os, assim, a uma nova moda, a das reuniões fechadas nos salões, surgindo o five o'clock tea.

Um personagem bastante comum nessa época foi o Dândi. O aparecimento do dandismo corresponde a um ideário no qual a figura se apresentava de uma maneira intelectualmente rebelde. Associado ao refinamento das classes sociais, esse sujeito interpreta uma postura própria da figura parisiense fin-du-siécle, que associada ao pessimismo e ao spleen, de Baudelaire, faz da sua presença nos salões, um perfil da realidade brasileira do momento. Sempre comentado nos jornais, a sua pose forçada, arquitetada para o requinte da hora, e o seu traço irônico, de personalidade irreverente, eram tidos como atitudes, muito embora paradoxais ao refinamento francês, comuns à sociedade carioca, capa de notícia das "modas e modos" de viver na Belle Époque.

À esta época de sonho e glamour, encerro com a poética de Greta Benitez, em Corselet,

\footnotetext{
Companheiro de festa

Lindo cúmplice escondido

Rendas espiãs curiosas

Que teimam em olhar a noite

Por uma fresta do vestido.
}
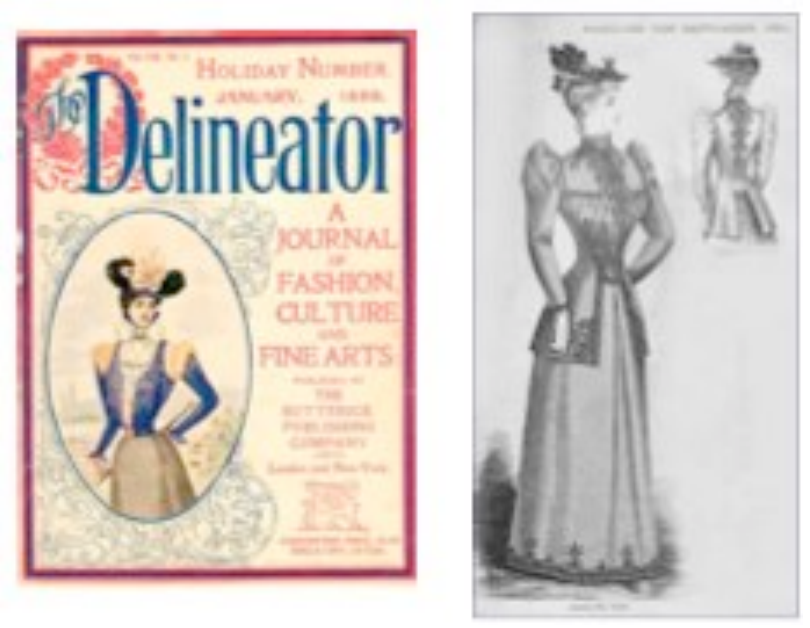

\section{Referências Bibliográficas}

BENCHIMOL, Jaime Larry. A Modernização do Rio de Janeiro. In BRENNA, Giovanna Del Rosso. O Rio de Janeiro de Pereira Passos: uma cidade

em questão II. Rio de Janeiro: Index, 1985.

BENITEZ, Greta. Corselet.

Disponível em www.geocities.com/gretabenitez/corselet/html

BRESCIANE, Maria Stella Martins. Londres e Paris no século XIX: o espetáculo da pobreza. São Paulo: Brasiliense, 1990. 
CARVALHO, Maria Alice Rezende de. Quatro vezes Cidade. Rio de Janeiro: Sete Letras, 1994.

JAGUARIBE, Beatriz. Fins de Século. Cidade e Cultura no Rio de Janeiro. Rio de Janeiro: Rocco, 1998.

MARINS, Paulo César Garcez. Habitação e Vizinhança: limites da privacidade no surgimento das metrópoles. IN História da Vida Privada no Brasil.República: da Belle Époque à era do Rádio. Vol 3, p. 131-214. São Paulo: Companhia das Letras, 2002.

PESAVENTO, Sandra Jatahy. Rio de Janeiro - uma cidade no espelho (1890-1910) In $\underline{\mathrm{O}}$ Imaginário da Cidade. Porto Alegre: UFRGS.1999.

PECHMAN, Robert Moses; Lima Junior, Walcler de. Flirts no footing da Avenida Central. Revista de História. Rio de Janeiro: Fundação Biblioteca Nacional, 2005, n 5, p. 34-37.

REIS, Ângela de Castro. Atuação, imagem pública e contexto social: o estudo de uma atriz na virada do século XIX: Cinira Polônio. Disponível em http://hemi.es.its.nyu.edu/por/seminar/brazil/angela.html

SEVCENKO, Nicolau. Literatura como Missão. São Paulo: Brasiliense, 1983.

O Prelúdio Republicano, astúcias da ordem e ilusões do progresso IN História da Vida Privada no Brasil.República: da Belle Époque à era do Rádio. Vol 3, p. 7-48. São Paulo: Companhia das Letras, 2002.

A capital irradiante: técnica,ritmo e ritos do Rio. IN História da Vida Privada no Brasil.República: da Belle Époque à era do Rádio. Vol 3, p. 513-619. São Paulo: Companhia das Letras, 2002. 